\title{
Study on the Time and Route of the Introduction of Ramayana into the Dai Ethnic Area of China
}

\author{
Yuyun Xue ${ }^{1, *}$ \\ ${ }^{1}$ Northwest Minzu University, Lanzhou, Gansu, China \\ *Corresponding author. Email: xueyuyun1111@126.com
}

\begin{abstract}
The general view is that the ancient Indian epic Ramayana was introduced to the Dai ethnic area of China with the introduction of Buddhism. Buddhism was introduced to the Dai ethnic area on a small scale at the beginning of the century or earlier, and Ramayana was also introduced to the Dai ethnic area at the same time or earlier. In fact, the commercial and cultural exchanges between China and ancient India were much earlier than this time. Before Buddhism was introduced, Ramayana might have been introduced to the Dai ethnic area. There are three routes for the introduction of Ramayana to the Dai ethnic area. The first route is to spread it by sea from southern India to Indonesia, Thailand, Burma, Laos and northern Vietnam, and then to the Dai ethnic area in Yunnan. The second route is from northern India to Tibet, China, and then to the Dai ethnic area through the Sichuan-Tibet highway. The third route is from the land through Bangladesh to Myanmar to the Dai ethnic area in Yunnan. The third route is the Sichuan-Yunnan-Burma-India Passage, a branch of the South Silk Road, and it is also a passage for direct exchanges between China and India without going by sea. The literature records that this passage was opened in the 4th century BC at the latest, but it didn't get the due attention in the academic circle for a long time.
\end{abstract}

Keywords: Ramayana, Introduction, Sichuan-Yunnan-Burma-India Passage, Dai ethnic area.

\section{INTRODUCTION}

Ramayana is one of the two epic poems of ancient India and is called the original poem. As the original poem, it not only had a profound influence on Indian literature, but also profoundly influenced Indian music, painting, sculpture, dance and other arts, and even influenced the establishment of Indian society's ideology, morality and religious beliefs. In India, Ramayana has long been wellknown and deeply rooted in the hearts of the people. Ramayana not only has a long-term and profound impact on the local history and culture of India, it has also spread to Central Asia, Europe, Southeast Asia and other places, and has a certain degree of influence on the literature of these places.

\section{THE INFLUENCE OF RAMAYANA ON DAI LITERATURE}

Regarding the forming time of the Indian epic Ramayana, scholars have different opinions. Most scholars believe that the writing date of the first copy of Ramayana was $500 \mathrm{BC}$, and the revised edition appeared in 200 BC. [1] This argument comes from the fact that Buddhism arose in $500 \mathrm{BC}$, and the name of Buddhism or Buddha was not mentioned in Ramayana, so it was written by 500 $\mathrm{BC}$ at the latest. There are seven chapters in Ramayana. Scholars believe that two to five chapters of it are made by one person. The author is the immortal Valmiki, and the first and seventh chapters are added later. The first and seventh chapters are different from the original in terms of style and writing techniques. [2] Therefore, the core part of Ramayana, namely, the second to fifth chapters, was completed in $500 \mathrm{BC}$, and the revised or added parts, namely, the first and seventh chapters, were completed in $200 \mathrm{BC}$.

Southeast Asia and India had a certain degree of contact in a very early period due to their geographical convenience. The earliest contact time of them was probably several centuries BC or earlier. The opportunity to contact means that the two civilizations have the opportunity to 
communicate and spread. Because the Chinese Dai people share the same ethnic origin and the same language as the Thai people on the peninsula, the Chinese Dai people have had direct or indirect exchanges with India for a long time.

The Dai nationality is a cross-border ethnic group, distributed in most areas of Yunnan, China, and Indo-China Peninsula. Because China's Dai ethnic area is closer to Indochina countries in terms of geography, national language, religious beliefs, etc., it is natural for Ramayana to spread northward to China's Dai ethnic area when it spreads in Southeast Asia. Facts have proved that Ramayana not only spread to the Dai ethnic area of China, but also had a huge impact on the literature, culture, and art of the Dai ethnic area. The result of literary influence is the production of the epic poem Lan $\mathrm{GaXiHe}$ (《兰嘎西贺》) of the Dai nationality.

In terms of population, the Dai people in Yunnan, China, are a small ethnic group, but the literature and art of this ethnic group with a population of only over 1.2 million are very developed, especially the large number of long narrative works. Hu Ba Meng, a poet and theorist of the Dai ethnic group, said that in the time he lived (about the 16th century AD), there were already 500 long narrative poems of the Dai ethnic group. The representative long narrative poems of the Dai people are the five sage poets: Wu Sha Ma Luo (《吾沙麻罗》), Zhan Ba Xi Dun (《沾巴西顿》), Lan Ga Xi He (《兰嘎西贺》), Ba Ta Ma Jia Peng Shang Luo (《巴塔麻戛捧尚罗》) and Nian Xiang (《粘响》). [3] Compared with the lyric characteristics of traditional Chinese literature, the narrative character of Dai literature is more eye-catching. In the environment where traditional Chinese literature is good at lyricism, the narrative of Dai literature shows strong "exotic" characteristics. This characteristic means that Dai literature has been more influenced by external influences, and this external influence may come from the influence of Indian literature.

"With the introduction of Buddhism, ancient Indian culture and Buddhist stories have gradually spread to the Dai ethnic area, which has had a profound impact on Dai literature. From then on, the phenomenon of re-creation based on ancient Indian myths or Buddhist stories has appeared in the literature circle of the Dai nationality. This phenomenon reaches its peak during the heyday of Buddhism. Lan Ga Xi He, known as one of the "five sage poets" of the Dai people, and Twelvehead Devil (《十二头魔王》), are works recreated based on the famous Indian epic Ramayana". [4] Academic world generally associates the introduction of Buddhism with the introduction of Indian culture and Buddhist stories, and believes that ancient Indian culture and Buddhist stories were introduced with the introduction of Buddhism. In fact, the introduction of cultural and literary stories must be earlier than the introduction of Buddhism. Because literature expresses the common emotion and universal value of human beings, it is easier to resonate and empathize with people from different regions, races, and even different civilizations. It is easier to be accepted by people than a kind of unfamiliar and cold religious knowledge. Also, because of its secularity, entertainment and popular nature, it doesn't require high knowledge of the disseminators, and it is easy for more disseminators to spread it in a wider range. The dissemination of religion has higher requirements for the disseminators, requires the disseminators to master professional knowledge, and is often accompanied by war and violence, with compulsive or even bloody force. The dissemination process is full of resistance, struggle and unwillingness, and the process of acceptance seems long and difficult.

Regarding the time when Buddhism was introduced into China's Dai ethnic area, Wang Song, in his book A Preliminary Study on the Development of Dai Poetry, believes that there were three periods: the first period should be at the beginning of the century or a little before. The dissemination route was directly from India or Sri Lanka to Burma, and then to the Dai ethnic area of China, but this time the missionary work was unsuccessful and Buddhism didn't hold a foothold in the Dai ethnic area; the second period was from the second to the twelfth centuries AD. The spread of Buddhism during this period was characterized by a fierce struggle with the primitive religion of the Dai nationality; in the third period, Buddhism began to build temples in various places and take root. The History of Dai Literature by Wang Song and others also believed that although Buddhist monks spread Buddhism to the Dai ethnic area as early as the first and second centuries AD, but the number was not large, and it had not yet established a foothold, let alone popularization. Around the seventh century $\mathrm{AD}$, the influence of Buddhism gradually expanded, and a universal belief was formed in the Dai ethnic area. [5] By the 8th century $\mathrm{AD}$, Buddhism gained a firm foothold in the Dai ethnic area. With the increasing commercial exchanges and Buddhist pilgrimages, the Rama 
story and the Rama story recorded in Buddhist scriptures gradually spread to the Dai ethnic area in China. This was the first stage in which the Dai people first knew the story of Rama. After the Rama story was introduced to the Dai ethnic area, because it was loved by the Dai people, it was sung, recited and processed, and gradually, it had Dai characteristics. From the 14 th to 15 th centuries AD, the story was created by the Dai poet Ying Da Wan into the Lan $\mathrm{Ga} \mathrm{Xi} \mathrm{He}$ with more than 12,000 lines. [6]

Ramayana was written in 500 BC. Before it was written, the story of Rama as an oral literature had been circulated in India for a long time. According to documentary records, the communication between China's Dai ethnic area and India began as early as the 4th century BC. In fact, the actual communication time must be earlier than this time. Therefore, the story of Rama entered the Dai ethnic area with trade caravans or others long before Buddhism was introduced. Listening to the story of Rama became a kind of pastime for merchants to spend a long night in a foreign land.

\section{RESEARCH ON THE TIME AND ROUTE OF THE INTRODUCTION OF RAMAYANA}

Wang Song and others' view on the introduction of Indian culture and religion into the Dai ethnic area in the first and second centuries AD are similar to those in the book The Story of Rama in India and Southeast Asian Literature by Zhang Yuan and Pei Xiaorui. Therefore, the story of Rama has spread to the Dai ethnic area during this time period. "Analyzed from various aspects, the time when the Rama story spread from India to the peninsula area via the southeast route may be early AD". [7] The Rama story was introduced to the Indochina Peninsula in the early $\mathrm{AD}$, and then further northward, it was possible to spread to the Dai ethnic area in the first and second centuries AD. If ancient Indian culture and Buddhist stories were introduced with the introduction of Buddhism, then they should have spread to the Dai ethnic area sporadically as early as the first and second centuries AD (or even earlier). And in the seventh and eighth centuries AD, they were spread to Dai ethnic area on a large scale, promoting the further prosperity of Dai literature, forming a golden age of Dai poetry represented by long story-style narrative poems.

In the book The Story of Rama in India and Southeast Asian Literature by Zhang Yuan and Pei
Xiaorui, the spread of the Indian Rama story to countries in the world is summarized into five routes, and the second, third, and fourth routes are related to the Dai ethnic area.

The second route is the northern line: it was from the east of India to Punjab Pradesh, Kashmir in the north. It was introduced into Xinjiang and Tibet from Kashmir, then into Han and Mongolian regions via the Hexi Corridor, and then into Japan via China.

The third route is the eastern line: it travelled by land through Bangladesh, and then spread to Myanmar, Thailand, Yunnan of China and Laos. This route is also known as the Sichuan-TibetBurma-India Passage in China.

The fourth route is the southeast line: it spread from southern India to Sri Lanka, then took the sea route through the Kra Isthmus, entered the Mon and Khmer settlements of the Southeast Asian Peninsula (the south-central part of the Southeast Asia Peninsula), and then, it spread from the Mon and Khmer settlements northward to other parts of present-day Burma, Thailand, Laos, and northern Vietnam.

Through the above three routes, Ramayana can be introduced into the Dai ethnic area.

The second route not only allows Ramayana to be introduced from Tibet to Han, Mongolian, and ethnic minority areas in Xinjiang, but it can also be introduced into Yunnan's Dai ethnic area through the Sichuan-Tibet highway. In the article The Sichuan-Tibet Highway Is the Earliest International Passage in Southwest China, Feng Hanyong believes that the route from Bashu to Shendu that Emperor Wu of the Han Dynasty wanted to open up was from Qiong, Zuo, Kunming, Tieqiao, and through Tubo. The starting point of this route is Qianwei (Yibin, Sichuan), and the end point is Kamrup (now Assam, India), which is adjacent to Tubo. This route is characterized by short distance and early opening time. This line is also known as Kunming Line A. Kunming Line B departs from Dali, passes through Tengchong and Gaoligong Mountain, crosses the Nmai Hka and MaliHka, and reaches India through the Savage Mountain. There are several other routes to Tubo first, and then from Lhasa down the Yarlung Zangbo River, and enter India via Motuo. Tibet is the link from the southwest to India. Its position is very important in the history of China's transportation, and its contribution to cultural exchanges is hard to estimate. [8] 
When Ramayana was spread through the fourth route, it was impossible to be directly spread to the Dai ethnic area in Yunnan of China. It was first spread to Myanmar, Thailand, Laos, and northern Vietnam. Because there were a large number of Dai people among the residents of these places, they belonged to the same ethnic group as the Dai people in Yunnan. Therefore, when it was spread, it had its own language, customs and other favorable conditions so that Ramayana was able to be advanced north to the Dai ethnic area in Yunnan. Bactria

The third route is spread by land, via Bangladesh, into Myanmar, Thailand, Yunnan of China and Laos. "Slightly later, the Rama story traveled eastward from India to Myanmar via Bangladesh, from Myanmar to the north and then to some ethnic minority areas in southwest China and Laos. There is a big difference between this kind of story and the text introduced via Java on the southern route, which is mainly due to the influence of the Bengali text and the Jain text". [7] It is believed that Ramayana was introduced to some ethnic minority areas in southwestern China slightly later than the beginning of $\mathrm{AD}$, which was roughly in line with the introduction of Buddhism to China in the first and second centuries AD in the History of Dai Literature by Yan Feng et al.

According to historical records, the SichuanYunnan-Burma-India Passage was opened before the second century BC. Records of the Historian • Biography of the Ethnic Minority Groups in Southwest China mentioned that: In the first year of Yuanshou, Emperor Wu of the Han Dynasty (122 BC), after Bowang Marquis Zhang Qian returned from his mission to Bactria, he said that he had seen the cloth and silk from Shu County and bamboo poles from Qiongdu when he stayed in Bactria. He asked people to ask about the source of these things, and the person who answered said: "They were obtained from the Shendu Kingdom in the southeast. The journey from here to there is thousands of miles. You can do business with merchants in Shu County". Some people heard that there was a Shendu Kingdom about 2,000 miles west of Qiongdu. Zhang Qian took the opportunity to harangue that Bactria was in the southwest of the Han Dynasty, admiring China, and worried that the Huns would block their vital communication line with China. If the road to Shu County could be opened, the road of Shendu Kingdom would be convenient and close, which would be beneficial to the Han Dynasty without any harmless. So Emperor $\mathrm{Wu}$ of the Han Dynasty ordered Wang Ranyu, Bai
Shichang, and Lv Yue and so on to find a shortcut from the west of western $\mathrm{Yi}$ to find the Shendu Kingdom. When they arrived in Dian Kingdom, Changqiang, the King of Dian, kept them and sent more than a dozen groups of people to the west to find the way for them. After more than a year, all the path-finding people were blocked by Kunming Kingdom and failed to lead to Shendu Kingdom. [9] In the first year of Yuanshou (122 BC), Zhang Qian saw the cloth and silk produced in Shu County and the bamboo poles produced in Qiongdu when he went to Bactria (an ancient country of the Western Regions). After inquiry, he was told that these products were from Shendu Kingdom (India), and people of Shendu Kingdom could do business with people from Shu County. Records of the Historian - Dawan Commentary Section records that: Shendu Country was thousands of miles southeast of Bactria, and there were products from Shu County, which showed that it was not far from Shu County. Nowadays, if you go to Bactria as an envoy, if you pass through the Qiang residential area, the terrain will be dangerous and the Qiang people will hate it; if you go a little bit north, you will be captured by the Huns. Going from the land of Shu County, it should be a straight road without any intruders. [9] At that time, the Huns and Qiang people in the north cut off the passage between the Central Plains and Bactria, and Emperor $\mathrm{Wu}$ of the Han Dynasty believed that the road in the Western Regions was difficult and dangerous, and the passage from Sichuan to Bactria through Yunnan and India was short and safe, so he sent people to look for this passage. As a result, it failed because of the obstacles from the Kunming tribe. Emperor $\mathrm{Wu}$ of the Han Dynasty's management in the southwest began in the sixth year of Jianyuan (135 $\mathrm{BC})$. The main action at this stage was to restore and renovate the two main traffic lines of the "Wuchi Path" and the "Maoniu Path", laying a solid foundation for finding a passage from Shu County to Shendu Kingdom. From the first year of Yuanshou (122 BC) to the sixth year of Yuanfeng (105 BC), it was the second stage of Emperor $\mathrm{Wu}$ of Han Dynasty's management of the southwest. In the early part of this period, the main purpose was to explore the passage to India, while in the later period; the main purpose was to open the passage from Yunnan to Burma. [10]

From the first year of Yuanshou (122 BC) to the first year of Yuanfeng (110 BC), after 11 years of exploration, Emperor $\mathrm{Wu}$ of the Han Dynasty finally found the general direction of the passage from Shu County to Shendu Kingdom. Records of 
the Historian - Dawan Commentary Section records that: Kunming and the like had no monarch and were good at robbery and steal, often killing and looting Han envoys, and the Han envoys failed to pass after all. However, it was heard that in a place more than a thousand miles west of Kunming, there was a country where the people ride elephants, named Dianyue. Some of the merchants who smuggled goods out of the Shu County had been there. [11]

There are many opinions about the geographic location of "Dianyue". Jiang Yuxiang quoted the views of five scholars here. [12] Their views on the geographic location of "Dianyue" can be roughly divided into three categories. The first view is that "Dianyue" is in India today, for example, Mr. Zhang Yi (Wenjiang) believes that "Dianyue" should be in the Kamarupa in Assam, India ${ }^{1}$; Mr. Tong Enzheng quoted Mr. Wenjiang's textual research in his article Archaeological Research on the Transportation of Southern China and India, and he believed that this view could be accepted. [13] The second view is that "Dianyue" is located in today's Yunnan Province. Mr. Xu Zhongshu believes that "Dianyue" is a halfway station from Kunming (Dali area) to India, a tribe west of Bao Son in ancient Yunnan; Mr. Fang Guoyu believes that Dianyue is the Tengchong of Yunnan today; Yunnan Dehong.com believes that "Dianyue" should refer to today's Dehong and its neighboring areas, and it is an important port on the "Shushen Dudao". The third view is that "Dianyue" is a country that straddles today's Yunnan and Myanmar. Mr. Yang Yongsheng believes that the "Riding-elephant Kingdom of Dianyue" is the "Kingdom of Daguang". The territory of the Daguang Kingdom includes the vast areas of northern Myanmar, central Myanmar and Shan State, as well as Dehong, Yunnan; in the History of Dai Literature edited by Yan Feng and others, there is also an explanation of the "Riding-elephant Kingdom of Dianyue": the Riding-elephant Kingdom, also known as Dianyue, and later was also called "Shan", that was, the "Shan State" recorded in Biography of the Ethnic Minority Groups in Southwest China - Biography of Ailao. This is the earliest regime of the Dai people. [14] They think that the "Riding-elephant Kingdom of

1. Regarding the view that "Dianyue" should be in the ancient country of Kamarupa in the Assam region of India today, it comes from Wenjiang's article Research on Dianyue Exploration of Early Sino-Indian Relations, which is included in The Collection of Studies on the South Silk Route edited by Duan Yu.
Dianyue" is the "Shan State". The "Shan State" is the original homeland of Taigong Kingdom named "Dingdui" in Myanmar. It is located on the banks of the Irrawaddy River, in the northeastern part of today's Myanmar. Book of the Later Han says: "The southwest of Shan State passes through Daqin (Rome)". [15] Whether the "Riding-elephant Kingdom of Dianyue" is in today's Yunnan, Burma, or Assam in India, it is indeed an important gate on the Yunnan-India Passage.

After finding the general direction to the Shendu Kingdom, Emperor Wu of the Han Dynasty devoted himself to opening up this passage, so he dispatched troops to Yunnan and set up states and counties. But when Emperor $\mathrm{Wu}$ of the Han Dynasty was alive, the envoys of the Western Han Dynasty never crossed the Ailao Kingdom to reach Burma. The passage from the Western Han Dynasty to the southwest was not opened, and the trade between the Western Han Dynasty and India could only be carried out indirectly through the tribes of the southwest. It was not until the twelfth year of Yongping (69 AD) of Emperor Mingdi of the Eastern Han Dynasty that the Ailao Kingdom was conquered, and the Yunnan-Burma section from Shu County to the Shendu Kingdom was completely unblocked. [16]

Since Zhang Qian discovered the products of Shu County of Western Han Dynasty in Bactria as early as $122 \mathrm{BC}$, it proved that this passage had been opened and used at an earlier time. In A Brief Discussion on the Foreign Trade in Chengdu Area in the Qin and Han Dynasties, Tong Enzheng believes that, starting from the Chengdu area, the commercial passage to Central Asia via Yunnan, Myanmar and India, which is called the South Silk Route later, is likely to have been initially opened during the Warring States Period. [17] Zhou Zhisheng also made this statement in Interflow Between Yunnan and India in Ancient Times: Nowadays, most scholars are inclined to the view that this passage has been opened by the end of the fourth century BC at the latest. [18] Compared with the Western Regions and the South China Sea passages, the Shu-Yunnan-Burma-India Passage is the earliest and the shortest passage between China and India.

French scholar G. Saides also mentions the problem of the transmission route of Indian culture in his book Indianized Countries in Southeast Asia. He believes that for the southern islands (Malay Peninsula), the introduction of Indian culture by sea is more convenient. But as far as Indochina 
(Indochina Peninsula) is concerned, has land also played a role? Some people think that although the land route is short and convenient, it is impassable because of the natural barriers of the Irrawaddy and Salween rivers, and the blockage caused by tropical plants. These difficulties were insurmountable at that time. Only in the age of aviation industry, these places are easily bypassed. G. Saides says that for adventurers or businessmen, the delta of Indochina (Indochina Peninsula) and its mangroves will not be more obstructive than the deserts of Central Asia and the heavy snow of Pamir, and the geographic obstacles will not be more terrible than pirates. He believes that in addition to the sea route, there was a road connecting India and China through Assam, Upper Burma and Yunnan. This road was clearly confirmed in the second century AD. In fact, its opening time can be traced back to the second century BC. Through this passage, after Indian culture influenced Upper Myanmar, it spread to Nanzhao. [19]

In summary, the passage between the Dai ethnic area in Yunnan and India was opened no later than the fourth century BC, and the two places had begun frequent and multi-directional exchanges.

\section{RAMAYANA WITH DAI CHARACTERISTICS}

In addition, historical materials in the Dai language $\mathrm{Ba}$ Ta Ma Ga Bo Han (《巴塔麻嘎波军》) and Bo La Na Tan (《波腊纳坦》) also have such records: "On the 523rd anniversary of the Buddha's death, Butaguoshating went to 'Lan $\mathrm{Ga}^{\prime}$ to participate in the recitation of Buddha scripture. After winning, the Buddhist scripture was officially promoted to the temple of the Buddha. It was first inscribed on the pattra leaves by Butaguoshating, and since then it was spread by water to 84,000 regional villages. At this time, at the time of the 526 years of the Buddhist calendar, the Pali language was introduced to the Dai ethnic area along with the Buddhist scriptures". [20] Butaguoshating's participation in the "Lan Ga" chanting was on the 523rd anniversary of the Buddhist calendar, which was in 19 BC. The data provided by these two Dai documents show that there were direct religious and cultural exchanges between the Dai ethnic area in Yunnan and the "Lan Ga" area in BC. This is also in line with Zhang Yuan's statement in The Story of Rama in India and Southeast Asian Literature, that is, "Analyzed from all aspects, the time when the story of Rama was introduced into the peninsula region via the southeast route from India may be early AD". Because of Butaguoshating's victory, the Buddhist scripture was ascended into the temple of the Buddha and was engraved on the pattra leaves and spread across 84,000 villages by water. This is also consistent with the time when Buddhism was first introduced into the Dai ethnic area (early AD or a little earlier).

Ramayana was introduced into China's Dai ethnic area along with Buddhism. The most powerful argument is that the Dai epic poem Lan $\mathrm{Ga} \mathrm{Xi} \mathrm{He}$ is based on Buddhism. After Buddhism was introduced to the Dai ethnic area, in order to expand its influence and make more people accept it, the best way was to popularize the Buddhist scripture, adapt various local literary stories, and add Buddhist elements. This is one of the commonly used and effective methods in the spread of Buddhism. Ramayana is widely spread in the Dai ethnic area and deeply rooted in the hearts of the people. It is inevitable that such stories will be adapted and used by Buddhism.

The strong vitality of oral literature makes it easier to spread; its popularity makes it easier to be accepted. Before Buddhism came into being, Ramayana had been circulated in ancient India. After it was introduced to the Dai ethnic area, it was spread there in the form of oral literature for a long time. When it was first introduced to the Dai ethnic area, Ramayana must carry a large number of original text features, such as information on Indian history, wars, culture, folklore, and religion. From the introduction to the writing of a book, it is not only a thousand-year-long dissemination process, but also a gradual localization process. During the long-term oral spread of Ramayana, the Dai people gradually turned it into a work full of Dai characteristics, that is, adding the ancient legend of the Dai people, and replacing the name of the hero in the original story with the name of their hero in Mengzhai. The "Large and Small Lan Ga" people see now, except for the story structure and main characters of Ramayana, are all Dai ethnicized. Later, the Dai language came into being, and the long-term oral chanting Ramayana was sorted into Lan Ga Xi He and Twelve-head Devil in the time of Payazhen. In Lan Ga Xi He, the various ancient Indian characteristics carried in Ramayana have been transformed into the characteristics of the Dai ethnic group. The religious aspect is particularly obvious, that is, the background of the story has changed from Hinduism to Southern Buddhism. 


\section{CONCLUSION}

As oral literature, it takes a long process from the beginning of the story, to the germination and generation, then to the completion of the book. Ramayana was written no later than $500 \mathrm{BC}$. Before it was written, it had a stronger communication power as an oral literature. The Dai people's literature records that local people went to Lan Ga to chant sutras in 19 BC. An earlier record is that Zhang Qian saw the cloth and silk produced in Shu County and the bamboo poles produced in Qiongdu in $122 \mathrm{BC}$. Due to the unique geographical location of China's Dai ethnic area, the time for exchanges with India may be earlier. As long as there is exchange, whether it is commercial exchange or official exchange, whether by land or sea, literature will be introduced with all kinds of exchanges. Oral literature, as the best pastime and comfort for trade caravans to spend the long nights in a foreign land, is easier for people to accept than commodity exchanges.

Therefore, the time when Ramayana was introduced into the Dai ethnic area was earlier than the time recorded in the existing classics. At the beginning of its introduction, it must have maintained its original appearance. Later, as Buddhism gained a foothold in the Dai ethnic area, Ramayana was deliberately adapted as a Brahmanism and became the Lan Ga Xi He that preached Buddhist doctrines; as a result, the characters and the whole story frame have gradually possessed Dai characteristics and Ramayana became the epic of the Dai people themselves.

\section{AUTHORS' CONTRIBUTIONS}

This paper is independently completed by Yuyun Xue.

\section{REFERENCES}

[1] Compiled by Ji Xianlin and Liu Anwu. A Compilation of Commentaries on Two Great Indian Epics [M]. Beijing: China Social Sciences Press, 1984.P.23. (in Chinese)

[2] Compiled by Ji Xianlin and Liu Anwu. A Compilation of Commentaries on Two Great Indian Epics [M]. Beijing: China Social Sciences Press, 1984.P.5. (in Chinese)

[3] Yanfeng, Wang Song, Dao Baoyao. The History of Dai Literature [M]. Kunming:
Yunnan Nationalities Publishing House, 1995.P.3. (in Chinese)

[4] Yanfeng, Wang Song, Dao Baoyao. The History of Dai Literature [M]. Kunming: Yunnan Nationalities Publishing House, 1995.P.499. (in Chinese)

[5] Yanfeng, Wang Song, Dao Baoyao. The History of Dai Literature [M]. Kunming: Yunnan Nationalities Publishing House, 1995.P.31. (in Chinese)

[6] Yanfeng, Wang Song, Dao Baoyao. The History of Dai Literature [M]. Kunming: Yunnan Nationalities Publishing House, 2014.P.509-510. (in Chinese)

[7] Zhang Yuan and Pei Xiaorui. The Story of Rama in India and Southeast Asian Literature [M]. Beijing: Kunlun Publishing House, 2008.P.60. (in Chinese)

[8] Feng Hanyong. The Sichuan-Tibet Highway Is the Earliest International Passage in Southwest China [J]. China Tibetology, 1989, 1. (in Chinese)

[9] Selected and edited by Geng Yinzeng. Chinese Science of Historical Data of South Asia [M]. Beijing: Peking University Press, 1990.P.3. (in Chinese)

[10] Editor-in-Chief, Jiang Yuxiang. Research on the Ancient Southwest Silk Road (Second Series) [M]. Chengdu: Sichuan University Press, 1995.P.3. (in Chinese)

[11] Editor-in-Chief, Jiang Yuxiang. Research on the Ancient Southwest Silk Road (Second Series) [M]. Chengdu: Sichuan University Press, 1995.P.5. (in Chinese)

[12] Editor-in-Chief, Jiang Yuxiang. Research on the Ancient Southwest Silk Road (Second Series) [M]. Chengdu: Sichuan University Press, 1995.P.37. (in Chinese)

[13] Tong Enzheng. Archaeological Research on the Transportation of Southern China and India [J]. Study and Explore, 1999,4. (in Chinese)

[14] Yanfeng, Wang Song, Dao Baoyao. The History of Dai Literature [M]. Kunming: Yunnan Nationalities Publishing House, 1995.P.9. (in Chinese) 
[15] Editor-in-Chief, Jiang Yuxiang. Research on the Ancient Southwest Silk Road (Second Series) [M]. Chengdu: Sichuan University Press, 1995.P.7. (in Chinese)

[16] Editor-in-Chief, Jiang Yuxiang. Research on the Ancient Southwest Silk Road (Second Series) [M]. Chengdu: Sichuan University Press, 1995.P.6. (in Chinese)

[17] Editor-in-Chief, Jiang Yuxiang. Research on the Ancient Southwest Silk Road [M]. Chengdu: Sichuan University Press, 1990.P.3. (in Chinese)

[18] Zhou Zhisheng. Interflow Between Yunnan and India in Ancient Times: A Historical Outline ( I ) [J]. South Asian Studies, 2002,1. (in Chinese)

[19] [France] G. Saides, translated by Cai Hua and Yang Baojun. Indianized Countries in Southeast Asia [M]. Beijing: The Commercial Press, 2018.P.56. (in Chinese)

[20] Compiled by Xishuangbanna Dai Autonomous Prefecture Ethnic Affairs Commission. A Brief History of Dai Literature $\quad[\mathrm{M}]$. Kunming: Yunnan Nationalities Publishing House, 1988.P.70. (in Chinese) 